\title{
When to change your tune? Unpaired and paired male house wrens respond differently to anthropogenic noise
}

\section{Original paper}

Article history:

Received: 30 March 2018

Accepted: 16 July 2018

Published: 3 September 2018

Check for updates

*Correspondence:

EEG: erin.e.grabarczyk@wmich.edu

\section{Peer review:}

Double blind

\section{Copyright:}

(c) 2018 Grabarczyk et al. @ This is an open access article distributed under the Creative Commons Attribution Non Commercial License (CC-BY-NC 4.0), which permits unrestricted use, distribution, and reproduction in any medium for noncommercial purposes only, provided the original work is properly cited and its authors credited.

\section{Keywords:}

bird song; anthropogenic noise; signal design rules; house wren; pairing status; playback experiment

\section{Citation:}

Grabarczyk E. E., Pipkin M. A., Vonhof M. J., and Gill S. A. (2018). When to change your tune? Unpaired and paired male house wrens respond differently to anthropogenic noise. Journal of Ecoacoustics. 2: \#LHGRVC.

https://doi.org/10.22261/JEA.LHGRVC

\author{
Erin E. Grabarczyk ${ }^{1 \star}$, Monique A. Pipkin², Maarten J. Vonhof ${ }^{3}$, Sharon A. Gill ${ }^{1}$ \\ ${ }^{1}$ Department of Biological Sciences, Western Michigan University, 1903 West Michigan Ave., \\ Kalamazoo, MI 49008-5200, USA \\ ${ }^{2}$ Ecology Program, The Pennsylvania State University, 221 Forest Resources Building, University \\ Park, State College, PA 16802, USA \\ ${ }^{3}$ Department of Biological Sciences, Institute of the Environment and Sustainability, Western \\ Michigan University, Kalamazoo, MI, USA
}

\section{Introduction}

A central premise underlying concern about the effects of anthropogenic noise on animal communication is that noise makes signals more difficult for receivers to detect and to discriminate. To improve detection probability, therefore, individuals alter their signals, increasing signal frequency to minimize masking (e.g. Slabbekoorn and Peet, 2003; Wood and Yezerinac, 2006; Mockford and Marshall, 2009), increasing signaling rate or duration to increase signal redundancy (e.g. Slabbekoorn and den Boer-Visser, 2006; Ríos-Chelén et al., 2013), and increasing signal amplitude to improve signal-to-noise ratios (Brumm, 2004; Dooling and Blumenrath, 2013; Derryberry et al., 2017). Assuming 
any costs of such adjustments are less than associated benefits (Read et al., 2013), signal changes should be favored if they improve detection in noisy environments and the chances of attracting breeding partners and defending space. Such changes should be most beneficial for callers when active space, the area over which the signal is broadcast, is large, when receivers are widespread, and when signals are not directed towards known receivers, such as when males advertise for female partners (Bradbury and Vehrencamp, 1999).

But should selection favor these same noise-induced adjustments once males have attracted females, when signal design rules (Bradbury and Vehrencamp, 1999) have changed? Across songbirds, males sing differently once paired, by decreasing song rate overall or singing at high rates during shorter periods (e.g. Krebs et al., 1981; Cuthill and Hindmarsh, 1985; Otter and Ratcliffe, 1993), by switching to different song types (Kroodsma et al., 1989; Eens et al., 1993; Staicer, 1996), and even by almost entirely ceasing to sing (Catchpole, 1973; Liu and Kroodsma, 2007). Paired males may also produce low-amplitude songs that likely only transmit to mates and possibly neighbors, but not beyond (Johnson and Kermott, 1991; Ritchison, 1995; Reichard et al., 2013). Because paired males direct their song at mates and neighbors over a smaller active space, they may not need to change their songs in noise or they may show different responses altogether, such as signaling less or not at all when encountering noisy conditions. Whether male responses to noise differs based on pairing status is poorly known, as few studies have focused on individually marked birds of known pairing status (but see Gross et al., 2010). Unpaired male reed buntings (Emberiza schoeniclus) increased song frequency on noisy versus quiet days, whereas paired males did not (Gross et al., 2010), providing correlative support for the idea that males alter their responses to noise depending on pairing status and signal design rules.

Differences in response between unpaired and paired males may occur if paired males experience different costs and benefits associated with signal adjustments in noise. Although changes in song structure are assumed to be beneficial, the ratio of benefits to costs could vary with pairing status, as well as more generally across breeding. For example, singing more loudly might reduce masking and increase the distance over which signals move (Nemeth and Brumm, 2010), yet additional energetic costs of such signaling (Lambrechts, 1996) might only be offset for unpaired males. Moreover, song preferences of females could constrain male options to adjust signals, such as in Great tits (Parus major), in which females prefer and show higher fidelity to males that sing low frequency song in noise (Halfwerk et al., 2011) and may seek other males if their partners produce altered song (Otter et al., 1999). Thus, fitness costs and benefits of noise-induced song changes may not be the same for all males. Addressing whether pairing status effects exist may reduce unexplained variation in male responses and improve our understanding of costs and benefits of signaling adjustments (e.g. Read et al., 2013).

We tested the hypothesis that male songbirds respond differently to noise depending on their pairing status. We studied a color-banded population of house wrens (Troglodytes aedon), a species in which males sing to attract mates (Johnson and Searcy, 1996), but once paired, males produce fewer shorter songs (Tove, 1988; Johnson and Kermott, 1991). We therefore expected that unpaired and paired males would sing differently, regardless of noise. Tropical house wrens alter their songs based on noise conditions (Redondo et al., 2013), thus, we expected northern wrens to change their songs due to noise as well. However, we reasoned that unpaired males would experience higher costs if noise masked their songs and they failed to attract or were delayed when attracting breeding partners (Habib et al., 2007; Gross et al., 2010). Paired males direct songs towards mates (Johnson and Kermott, 1991; LaBarbera et al., 2010) and nearby territorial males and nesting females (most extra-pair offspring are fathered by neighboring males, Johnson et al., 2002). Thus, we predicted unpaired males would alter their songs when exposed to noise to improve detection, but paired males either would not alter their songs at all or would sing less under noisy conditions.

To test our hypothesis, we synthesized pink noise and played it at three intensities within the territories of paired and unpaired focal males, recorded their songs, and analyzed whether song structure varied with pairing status and noise treatment. We also validated two assumptions of noise playback experiments. First, to test the assumption that noise playbacks do not affect measurement of spectral features of male songs, we sequentially played each noise treatment while simultaneously playing the same pre-recorded house wren songs. Because prerecorded song will not change across treatments, any differences in song traits detected during analysis should be attributed to the noise playback and those traits should be omitted from consideration (Verzijden et al., 2010; Hanna et al., 2011). Second, we tested the assumption that noise playbacks change noise levels during trials on focal male territories (Halfwerk and Slabbekoorn, 2009; LaZerte et al., 2016; Ríos-Chelén et al., 2017a). If noise playbacks do not consistently change noise levels, any song changes that occur during focal male trials cannot be ascribed to noise treatments. 


\section{Study species and sites}

We studied a migratory population of house wrens breeding in nest boxes at five nature preserves in Kalamazoo County, Michigan, USA (42.290 N, 85.586 W). Each site has mixed forest and open grassland preferred by house wrens, but sites varied in the amount of surrounding urbanization (impervious surface) and distance to sources of continuous (e.g. highways) and intermittent noise (e.g. local roads; Gill et al., 2017). We captured house wrens by mist net and fitted them with unique combinations of three color bands and one numbered aluminum band for individual identification. We sexed males in hand based on their cloacal protuberance and confirmed sex by observing singing. Male house wren song consists of two sections: an introduction composed of low amplitude notes with multiple harmonics (Rendall and Kaluthota, 2013) followed by a high-amplitude, frequency modulated terminal portion (Platt and Ficken, 1987; Figure 1). Unlike the terminal portion which transmits beyond territory boundaries (Tove, 1988), the introduction is not consistently recorded even in low noise conditions (Rendall and Kaluthota, 2013); therefore, we analyzed features of terminal portions only.

We checked nest boxes every three days to determine if they were occupied by males, and whether males had paired. Females can be difficult to detect during early days of pairing, therefore, we determined pairing status by observing male behavior around their boxes and stages of nest construction. Unpaired males sing at high rates from perches around $25 \mathrm{~m}$ high, whereas paired males sing at lower heights and near their nests (Johnson and Kermott, 1991). In terms of nest construction, males build nest platforms, whereas females build nest cups and add lining (McCabe, 1965). Thus, we noted when cups began forming or were being lined, in addition to direct observations of females building to determine if and when males had paired. After testing, we continued to monitor focal males to determine if unpaired males eventually paired or remained unpaired over the breeding season.

\section{Noise synthesis}

Anthropogenic noise may occur continuously, such as noise generated from gas compressors or building ventilation systems, or intermittently, such as from passing cars (Gill et al., 2017). Using naturally recorded anthropogenic noise in playback experiments can be problematic if noise is not constant, as it is not possible to isolate whether animals responded to fluctuations in sound pressure levels due to intermittent noise or to mean levels of continuous noise. Given such variation, adequately describing noise levels to which animals are exposed may be difficult (Shannon et al., 2015). For our experiments, we therefore synthesized pink noise, which is a 1/f noise with energy concentrated at lower frequency bands resembling continuous noise from urban environments and traffic (Figure 2). We generated 5-min of pink noise in Avisoft SASLab Pro v 5.1 (R. Specht, Berlin, Germany; $44.1 \mathrm{kHz}$ sample rate, low-pass $1 / \mathrm{f}$ frequency cut off at $0.20 \mathrm{~Hz}, 1-6 \mathrm{~Hz}$ bandpass filter) and to avoid startling the birds, we gradually increased noise intensity over $5 \mathrm{~s}$ at the beginning of the recording. In Audacity v 2.1.2, we then twice amplified the original signal by $15 \mathrm{~dB}$, resulting in low, moderate, and high intensity noise playback files. In the field, we set the lowest amplitude playback to $50 \mathrm{dBA}$ at $1 \mathrm{~m}$ and confirmed the remaining two at 65 and 80 dBA with a SPL meter (American Recorder Technology SPL-8810). We then applied the same settings to all experiments.

\section{Validation experiment}

We used the automated measurement tool in Avisoft to quantify frequency traits as recommended by recent studies (Zollinger et al., 2012; Brumm et al., 2017; Ríos-Chelén et al., 2017b). Extracting frequency traits with

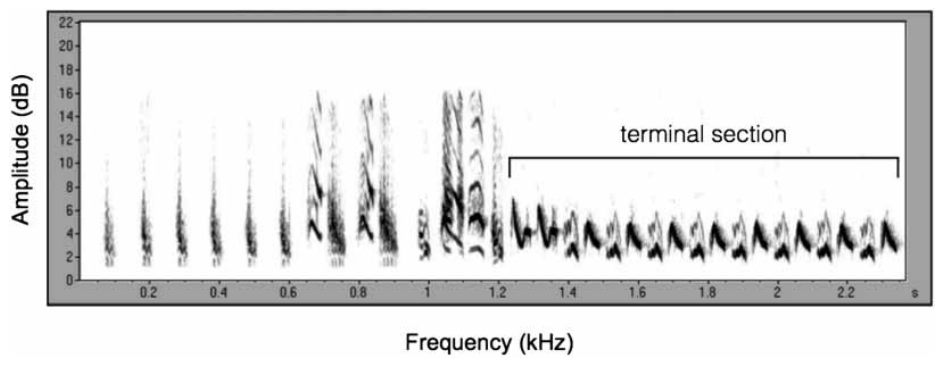

Figure 1. Spectrogram of house wren song, highlighting the two sections of the song. We measured the frequencymodulated terminal section, which is capable of transmitting beyond a male's territory (Tove, 1988). 

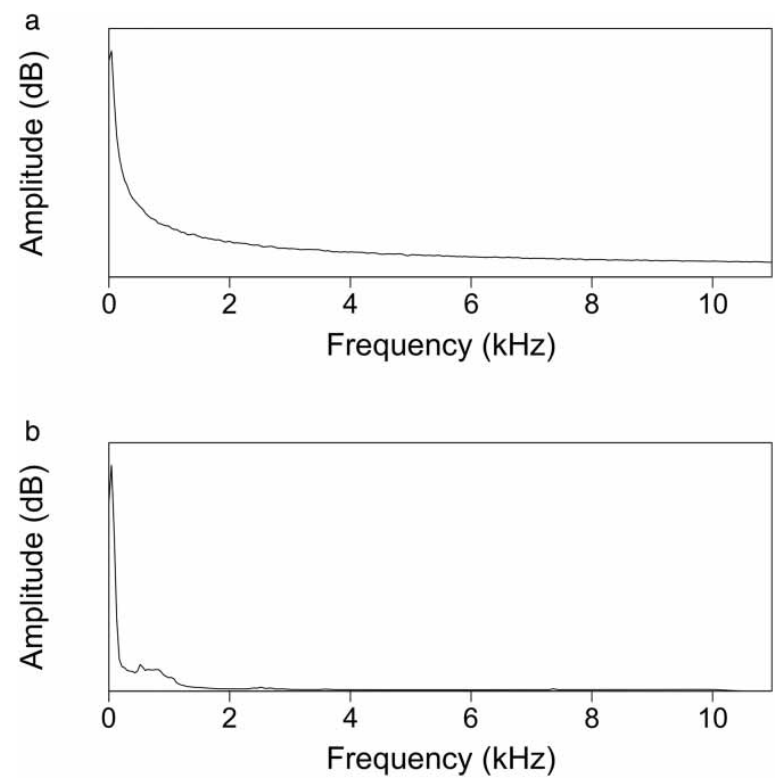

Figure 2. Power spectrum of synthesized pink noise (a) shows high amplitude noise peaks at low frequencies (appx $0-2 \mathrm{kHz}$ ) and tapers off with increasing frequency. Pink noise reflects naturally occurring patterns of continuous anthropogenic noise (b) and eliminates intermittent peaks in SPL that may be present in recordings of anthropogenic noise.

an automated tool without influence from noise can be difficult, particularly with high background noise, as the program may use input from noise rather than solely from song (Verzijden et al., 2010; Cardoso and Atwell, 2011). Therefore, to test whether noise playback influenced measurement of spectral traits, we conducted a validation experiment during which we paired the playback of two repetitions of 10 pre-recorded house wren songs with each of four treatments: low noise, moderate noise, high noise, and control without noise (Verzijden et al., 2010). We attached one SME-AFS amplified speaker (Saul Mineroff Electronics, New York) to the top of an unoccupied nest box to simulate a singing male and set a second speaker on the ground $10 \mathrm{~m}$ from the nest box as in our experimental trials (see below). We re-recorded songs with a Wildlife Acoustics SongMeter 2 (SM2, Maynard MA; $44.1 \mathrm{kHz}$ sample frequency, 16-bit) positioned $1 \mathrm{~m}$ in front of the nest box at speaker height. In Avisoft, we analyzed frequency traits of pre-recorded songs from each noise treatment and the control. If song frequency traits varied across treatments, we would not be able to conclude that changes in frequency traits in focal male experiments were due to adjustments by males or were artifacts of noise playbacks. Thus, for focal male experiments, we omitted frequency traits that varied with treatment in the validation experiment.

\section{Playback experiment}

We performed focal male experiments $(N=31)$ between sunrise and 1100 (EST) and used a Wildlife Acoustics SongMeter 2 (SM2, Maynard MA; $44.1 \mathrm{kHz}$ sample frequency, 16-bit) to record the songs of focal males. We attached the SM2 microphone to the focal male's nest box and connected the microphone to the recording unit using a 10-m cord. We placed an SME-AFS amplified speaker from which we broadcast noise on the ground $10 \mathrm{~m}$ from the nest box. To minimize disturbance during trials caused by our presence, we connected the speaker to an Apple iPod (Cupertino, CA) using a $20 \mathrm{~m}$ extension cable. We recorded a 5-min control period without any playback and started the 5-min noise playback when focal males arrived within $10 \mathrm{~m}$ of their nest boxes. We randomized the order of noise treatments and allowed a 10-min break between trials before presenting the next stimulus to minimize carry-over effects.

\section{Song and noise analysis}

Prior to analysis in Avisoft, we removed low- and high-frequency sounds from recordings using a bandpass filter $(1.3-11 \mathrm{kHz})$ on waveforms. We converted filtered waveforms into spectrograms (Flat top window, FFT length of 512, 93.75\% overlap, $0.725 \mathrm{~ms}$ time resolution) and extracted minimum frequency $(\mathrm{Hz})$, maximum frequency $(\mathrm{Hz})$, peak frequency $(\mathrm{Hz})$, and bandwidth $(\mathrm{Hz})$ using automated parameter measurements. For minimum and maximum frequency, we set a measurement threshold of $-10 \mathrm{~dB}$ below peak frequency on the 
power spectrum. We chose this threshold because it was the lowest value that led to consistent measurement of song rather than remaining noise that overlapped song across all noise treatments. We also measured song length (s) and singing rate (songs/min) across treatments.

To test the assumption that noise playbacks altered sound pressure levels (SPLs) in territories of focal males, we measured SPLs during each treatment as well as the control period. We calibrated each microphone and SM2 unit pair by recording a 94-dB tone generated by a Larson Davis CAL 200 sound level calibrator (Depew, NY). Using the Calibration function in Avisoft, we set the relative amplitude of the recording to $0 \mathrm{~dB}$ (re $20 \mu \mathrm{Pa}$ ) based on the calibration tone, then randomly selected and averaged SPLs (RMS, dB) from five 1-s samples of recording, not overlapped by house wren song, from each treatment and the control.

\section{Statistical analysis}

We conducted all analysis using R statistical software v 3.3.1 (R Core Development Team 2016). To test whether noise playback affected measurement of frequency traits in the validation experiment, we ran a linear mixed model using the package nlme (Pinheiro et al., 2017), with noise treatment as a fixed effect and song number as a random effect (we played twice each of 10 unique songs in this experiment). We tested whether noise treatments altered SPLs in focal territories by comparing average SPLs during treatments with a linear mixed model, with treatment as a fixed effect and male identity as a random effect to account for repeated noise measurements. We used the package lsmeans (Lenth, 2016) to run pairwise comparisons to determine which treatments differed in each of these tests.

To test the main hypothesis that noise and pairing status influenced singing, we analyzed only those songs clearly visible on the spectrogram window and not those overlapped by other sounds. We calculated mean values of each song trait by individual per treatment (control: mean $=19.7$ songs, range $=2-59$ songs; high noise: mean $=14$ songs, range $=0-50$ songs). We then used a linear mixed model, with treatment and pairing status as fixed effects and male identity as a random effect to account for the repeated measures design in which the songs of each individual were compared across treatments. We explored whether an interaction term with treatment and pairing status should be included in the final model by comparing AICc of the main effects and interaction models. The model with the lowest AICc was considered the best fit if AICc of the second model differed by more than 2 (Burnham and Anderson, 2002). Residual plots were explored to assess model adequacy. We plotted residuals from each model against SPLs measured within individual territories to determine whether ambient SPLs may explain residual variation, but found no patterns in these plots. All figures were created with the package sciplot (Morales, 2012).

\section{Results}

\section{Validation experiments}

We tested the assumption that noise playbacks have no effect on measurement of frequency traits. Minimum frequency $\left(F_{3,57}=23.46, p=<0.0001\right)$, maximum frequency $\left(F_{3,57}=18.93, p=<0.0001\right)$, peak frequency $\left(F_{3,57}=\right.$ 3.97, $p=0.01)$, and bandwidth $\left(F_{3,57}=26.59, p=<0.0001\right)$ each differed significantly among treatments. Post-hoc pairwise comparisons showed complex and somewhat unpredictable differences across traits and treatments. For example, minimum frequency was higher during high-noise playbacks and lower during low-noise playbacks than controls, but did not differ between moderate noise playbacks and controls. Minimum frequency likely increased under high noise because filtering failed to remove from the waveform all the energy generated by the playback. By contrast, peak frequency differed only between low noise and control treatments; this result appeared to be driven by two songs, which had higher peak frequency during the low noise treatment than the others. This could be due to irregular amplitude fluctuations during signal transmission, which result from temporary shifts in wind speed or air temperature (Wiley and Richards, 1978). Noise playbacks did not affect measurement of song rate or length.

We next tested the assumption that noise playbacks alter sound pressure levels within focal territories. Ambient SPLs did not differ between control periods (mean $\pm \mathrm{SD}=47.7 \pm 5.07 \mathrm{~dB}$, range $=36.9-53.7 \mathrm{~dB}$ ) and low (mean \pm SE difference between noise and ambient SPLs: $-0.7 \pm 0.7 \mathrm{~dB}, t_{90}=-1.00, p=0.31$ ) or moderate $\left(0.7 \pm 0.7 \mathrm{~dB}, t_{90}=0.98, p=0.32\right)$ noise treatments. High noise treatments increased SPLs by $5.12 \pm 0.7 \mathrm{~dB}$ $\left(t_{90}=7.29, p=<0.0001\right)$ compared to all other treatments. We further explored the degree to which the high noise treatment changed SPLs and noted that in 14 cases, the high noise playback changed SPLs by $<3 \mathrm{~dB}$, a difference which birds may not detect (Dooling, 1982). In our final analysis, therefore, we omitted low and 
moderate noise playbacks (which did not change SPLs relative to ambient levels) as well as high noise playbacks that had a minor effect on SPLs $(<3 \mathrm{~dB})$. This left us with 17 experiments on male house wrens for which we could compare song traits between control and high-noise treatments (mean \pm SE difference in SPL between these treatments and controls: $8.86 \pm 3.59 \mathrm{~dB}$ ). Furthermore, we analyzed peak frequency, as this trait did not differ between control and high-noise treatments in the validation experiment (above).

\section{Responses of unpaired and paired males to noise playbacks}

We compared a model including the interaction between treatment and pairing status to a main effects model without interactions and found the interaction model best fit the data on peak frequency $(\triangle \mathrm{AICc}=3.31$, AICc main effects $=449.96$, AICc interaction $=446.65)$. During high-noise playbacks, paired males shifted their song by singing at a higher peak frequency, whereas unpaired males did not adjust peak frequency in response to noise. The peak frequency of songs of paired and unpaired males during control periods did not differ (Figure 3).

For temporal traits, models with and without the interaction between treatment and pairing status did not differ (rate: $\triangle \mathrm{AICc}=2.67$, AICc main effects $=186.63$, AICc interaction $=189.3$; length: $\triangle \mathrm{AICc}=3.13$, AICc main effects $=9.04$, AICc interaction $=12.17)$, therefore, we analyzed the main effects model only. On average, unpaired males sang $4.93 \pm 1.17$ songs/min more than paired males $\left(t_{15}=4.2, p=0.008\right)$, but noise treatment had no effect on song rate. Unpaired males sang $0.23 \pm 0.1 \mathrm{~s}$ longer songs than paired males $\left(t_{15}=2.31\right.$, $p=0.04$ ), but again noise treatment had no effect on song length (Figure 4). Of all the unpaired males tested $(N=16), 10$ eventually paired and six remained unpaired during the breeding season.

\section{Discussion}

We tested the hypothesis that male house wrens adjust their song differently in response to anthropogenic noise based on whether they are unpaired or paired. Consistent with previous studies on house wrens (Tove, 1988; Johnson and Kermott, 1991), unpaired and paired males sang differently during experiments, with unpaired males singing longer songs at higher rates than paired males. Contrary to predictions, however, it was paired males that changed their songs in response to noise playbacks: they increased peak frequency of their songs during high noise playback, whereas unpaired males did not. Males, regardless of pairing status, did not adjust the temporal features of their songs in response to noise.

Given that song adjustments improve detection in noise (Pohl et al., 2009, 2012; LaZerte et al., 2017) and males sing to attract females from unknown locations (Bradbury and Vehrencamp, 1999), unpaired males should experience greater benefits than paired males from changing their songs in noise. Accordingly, we predicted that unpaired, not paired males, would alter song frequency in noise. During control periods, paired and unpaired males produced songs with similar peak frequencies, suggesting that under ambient conditions, whether males

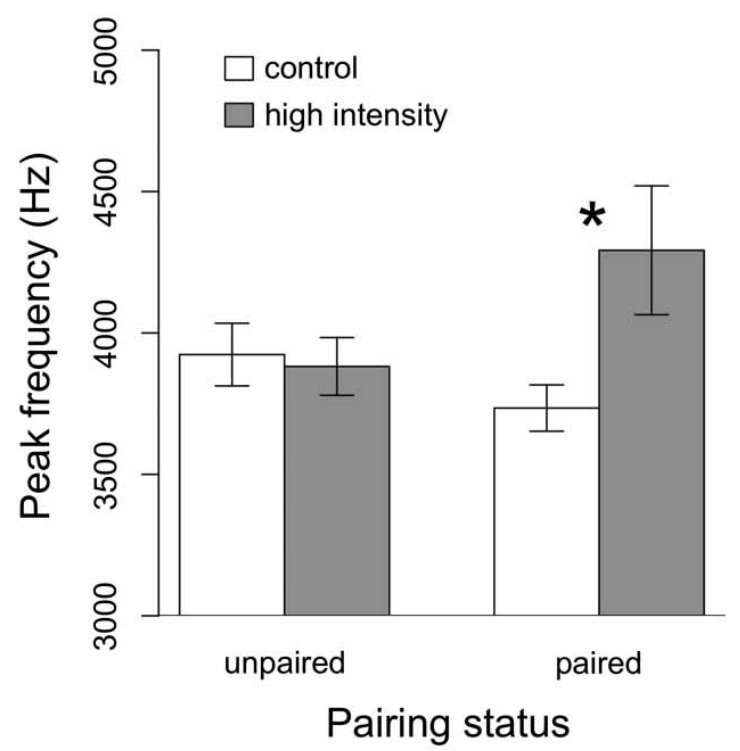

Figure 3. Paired male house wrens increased the peak frequency of their songs during high noise playback compared to the control. Unpaired male house wrens did not adjust peak frequency. 

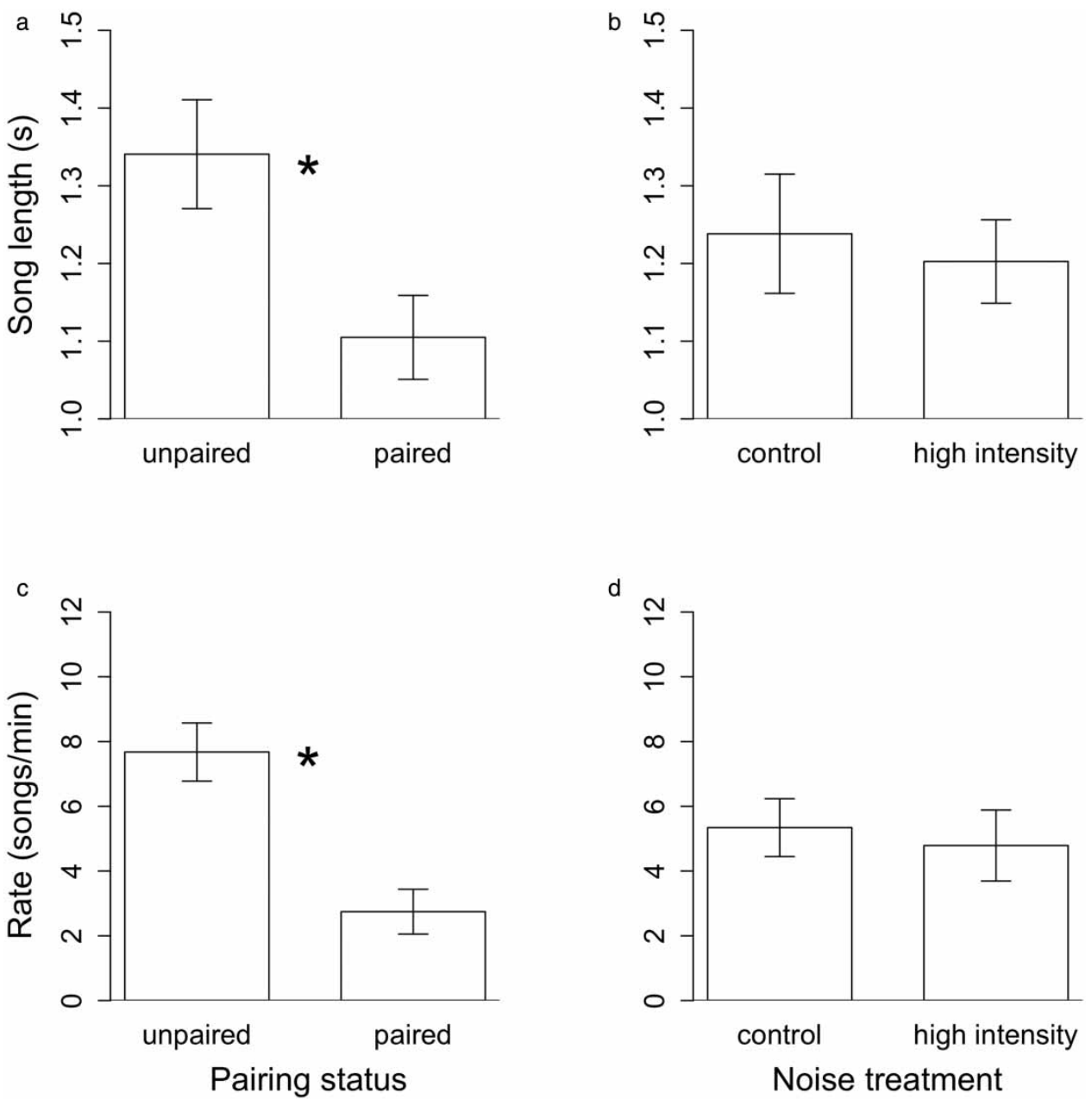

Figure 4. Unpaired male house wrens sang longer songs (a) at a higher rate (c) than paired males, however noise treatment had no effect on song length (b) or rate (d).

were paired had limited or no influence on song frequency. During noise playbacks, paired males increased song frequency, but unpaired males did not, maintaining similar peak frequencies under quiet and noisy conditions (Figure 3). Female house wrens are attracted to male song (Johnson and Searcy, 1996), but while trill consistency and vocal deviation are not used by females in mate choice decisions (Cramer, 2013), other song traits, including peak frequency, have not been ruled out. Male great tits that sing at low frequencies in noisy conditions during female fertile periods are more likely to maintain paternity in their clutches (Halfwerk et al., 2011). Alternatively, male chestnut-sided warblers (Dendroica pensylvanica) that sing consistent songs at a high frequency fathered more extra pair offspring (Byers, 2007). If peak frequency indicates male quality in house wrens, unpaired males may be constrained by female preferences to produce low frequency song regardless of noise background. Paired males in our study population could be viewed as higher quality as they have already paired. Moreover, because they quickly adjust their song in noise, they may be more detectable to neighboring females, allowing them to acquire additional fitness through extra-pair offspring.

How a male adjusts song frequency in response to increasing ambient noise could depend on prior experience with signaling in noise. Black-capped chickadees (Poecile atricapillus) in noisy habitats increased song frequency in response to noise playbacks, whereas males in quiet areas decreased song frequency, producing songs that were more difficult to detect in noise (LaZerte et al., 2016). If noise adjustments are learned and vary with experience, then the ability to adjust songs based on ambient sound conditions may improve with age. All males in our study bred in urban or peri-urban natural areas, thus we assumed they had prior exposure to anthropogenic noise. Responses were not influenced by background noise levels on male territories, but because unpaired males did not adjust songs to reduce noise masking, they could be younger and less experienced with signaling in noise. However, additional work is needed to test whether individual experience or age modifies responses of house wrens and other species to noise.

Consistent with previous studies (Tove, 1988; Johnson and Kermott, 1991), male house wrens structured temporal song characteristics differently based on pairing status. Unpaired males sang longer songs at a higher 
rate than paired males, similar to findings in other taxa, in which longer songs given at high rates are often used for long-distance communication (e.g. Nelson and Poesel, 2011). For males to attract mates their signals must be detectable, but also, importantly, localizable by listening females (Bradbury and Vehrencamp, 1999). To be localizable, males sing at high rates (Bradbury and Vehrencamp, 1999), which enables females to cue in on multiple renditions of songs and determine a male's location (Klump, 2000). However, neither unpaired or paired males changed song rate or length due to noise playback. In noise, longer songs (Ríos-Chelén et al., 2013) and song repetition (Brumm and Slater, 2006) may increase the probability of signal detection by increasing redundancy. Because unpaired males already sing long songs at high rates but do not adjust temporal song features in noise, it is possible they already sing at physiological capacity (mean $\pm S D$ unpaired male song rate: $8.02 \pm 2.02$ songs/ min; E. Grabarczyk, unpublished data). Perhaps unpaired males in our study signal at high rate with preferred traits; if noise is constant then their signals will likely be masked, but if noise is intermittent, then some songs may reach listening females. Assuming a cost of singing in noise, paired males may experience little or no benefit from increasing signal redundancy: their signals are likely to reach the primary receivers of their songs, their mates and neighbors. Nevertheless, paired males do produce signals that may be more detectable in noise.

Assessing song adjustments to introduced noise presents challenges different from playback studies exploring other auditory stimuli, such as songs or alarm calls. Studies using playback experiments assume that focal individuals detect a given stimulus and distinguish it from other stimuli being presented. In the case of song or alarm calls, the rather obvious change in behaviors that follow from playbacks (e.g. increased singing and approach to the speaker to songs, and fleeing or holding still to alarm calls (Gill and Sealy, 2004)) signal to observers that both detection and discrimination have occurred. When individuals fail to respond, we assume the signal had no salient features to trigger a response in the context in which it was played, but an alternative explanation is that the signal was not detected by the intended receiver. This consideration is critical when exploring how animals alter their signals in response to anthropogenic noise using playbacks: do playbacks meaningfully change the sound environment of singing males to the point where males detect, discriminate, and then alter their songs?

We assessed two assumptions of noise playback experiments: whether noise playbacks affect measurement of spectral traits (Verzijden et al., 2010; Hanna et al., 2011) and whether noise playback altered SPLs on focal male territories during trials (Halfwerk and Slabbekoorn, 2009; LaZerte et al., 2016; Ríos-Chelén et al., 2017a). Our validation experiment showed that noise playback affected minimum, maximum and frequency bandwidth values extracted with the automated parameter tool and we therefore eliminated these traits from analysis. Failure to assess if noise playback influences song measurement could result in false positives, particularly of frequency values, and changes detected could be artifacts of playbacks rather than adjustments by focal males (Brumm et al., 2017; Ríos-Chelén et al., 2017b). Moreover, by extracting SPLs from recordings made using calibrated microphone and recording unit pairs, we found that only 17 out of 31 high-intensity noise playbacks effectively altered noise levels on focal male territories. Accordingly, we eliminated trials with no appreciable change in noise to focus on those that meaningfully changed the sound environment. Without quantifying the extent to which noise playbacks alter noise levels, researchers risk misinterpreting experimental results that are needed to advance knowledge of noise effects on communication.

Anthropogenic noise has the potential to disrupt acoustic communication and could have detrimental impacts on fitness. Understanding why animals adjust their signals is critical for understanding how to mitigate negative effects of noise. Contrary to predictions, we showed that unpaired male house wrens did not alter singing in noise whereas paired males did. For unpaired house wrens, producing low frequency song at high rates may be more important for mate attraction and female choice than increasing song frequency to overcome noise masking. Paired males however may risk less by changing their song frequency as they have already mated. Thus, vocal adjustments in noise may not benefit all males in the same way within a breeding population.

\section{Acknowledgements}

We thank N. Faison and A. Abe for field assistance and S. Beuerle for assistance calibrating recording units and microphones. We thank the Southwest Michigan Land Conservancy, especially N. Fuller, and Western Michigan University, especially S. Keto, for permitting our research. We also thank two anonymous reviewers for their helpful comments.

\section{Funding sources}

This work was supported by a grant from the NSF to S. A. Gill and K. Naghshineh (IOS-1257699). M. A. Pipkin was supported by a scholarship from the Lee Honors College at Western Michigan University and MPI Undergraduate Research Award. 


\section{Competing interests}

Erin Grabarczyk, Monique Pipkin, Maarten Vonhof and Sharon Gill declare they have no conflict of interest.

\section{References}

Bradbury J. W. and Vehrencamp S. L. (1999). Principles of Animal Communication, 1st ed. Sunderland (MA): Sinauer Associates.

Brumm H. (2004). The impact of environmental noise on song amplitude in a territorial bird. Journal of Animal Ecology. 73 (3): 434-440. https://doi.org/10.1111/j.0021-8790.2004.00814.x

Brumm H. and Slater P. J. (2006). Ambient noise, motor fatigue, and serial redundancy in chaffinch song. Behavioral Ecology and Sociobiology. 60 (4): 475-481. https://doi.org/10.1007/s00265-006-0188-y

Brumm H., Zollinger S. A., Niemelä P. T., and Sprau P. (2017). Measurement artefacts lead to false positives in the study of birdsong in noise. Methods in Ecology and Evolution. 8 (11): 1617-1625. https://doi.org/10.1111/2041-210X.12766

Burnham K. P. and Anderson D. R. (2002). Model Selection and Multimodel Inference. A Practical Information-Theoretic Approach. 2nd ed. New York: Springer Science \& Business Media.

Byers B. E. (2007). Extrapair paternity in chestnut-sided warblers is correlated with consistent vocal performance. Behavioral Ecology. 18 (1): 130-136. https://doi.org/10.1093/beheco/arl058

Cardoso G. C. and Atwell J. W. (2011). On the relation between loudness and the increased song frequency of urban birds. Animal Behaviour. 82 (4): 831-836. https://doi.org/10.1016/j.anbehav.2011.07.018

Catchpole C. K. (1973). The functions of advertising song in the sedge warbler (Acrocephalus schoenobaenus) and the reed warbler (A. scirpaceus). Behaviour. 46 (3): 300-319. https://doi.org/10.1163/156853973X00067

Cramer, E. R. A. (2013). Physically challenging song traits, male quality, and reproductive success in house wrens. PLoS ONE. 8 (3): e59208. https://doi.org/101371/journal.pone.0059208

Cuthill I. and Hindmarsh A. (1985). Increase in starling song activity with removal of mate. Animal Behaviour. 33 (1): $326-328$. https://doi.org/10.1016/S0003-3472(85)80146-9

Derryberry E. P., Gentry K., Derryberry G. E., Phillips J. N., Danner R. M., et al. (2017). White-crowned sparrow males show immediate flexibility in song amplitude but not in song minimum frequency in response to changes in noise levels in the field. Ecology and Evolution. 7 (13): 4991-5001. https://doi.org/10.1002/ece3.3037

Dooling R. J. (1982). Auditory perception in birds. In: Acoustic Communication in Birds, vol. 1. New York: Academic Press, 95-130.

Dooling R. J. and Blumenrath S. H. (2013). Avian sound perception in noise. In: Animal Communication and Noise, edited by Brumm, H. Berlin Heidelberg: Springer. 229-250.

Eens M., Pinxten R., and Verheyen R. F. (1993). Function of the song and song repertoire in the European starling (Sturnus vulgaris): an aviary experiment. Behaviour. 125 (1): 51-66.

Gill S. A. and Sealy S. G. (2004). Functional reference in an alarm signal given during nest defence: seet calls of yellow warblers denote brood-parasitic brown-headed cowbirds. Behavioral Ecology and Sociobiology. 56 (1): 71-80. https://doi.org/10.1007/s00265-003-0736-7

Gill S. A., Grabarczyk E. E., Baker K. M., Naghshineh K., and Vonhof M. J. (2017). Decomposing an urban soundscape to reveal patterns and drivers of variation in anthropogenic noise. Science of the Total Environment. 599: 1191-1201. https://doi.org/10.1016/j. scitotenv.2017.04.229

Gross K., Pasinelli G., and Kunc H. P. (2010). Behavioral plasticity allows short-term adjustment to a novel environment. The American Naturalist. 176 (4): 456-464. https://doi.org/10.1086/655428

Habib L., Bayne E. M., and Boutin S. (2007). Chronic industrial noise affects pairing success and age structure of ovenbirds Seiurus aurocapilla. Journal of Applied Ecology. 44 (1): 176-184. https://doi.org/10.1111/j.1365-2664.2006.01234.x

Halfwerk W. and Slabbekoorn H. (2009). A behavioural mechanism explaining noise-dependent frequency use in urban birdsong. Animal Behaviour. 78 (6): 1301-1307. https://doi.org/10.1016/j.anbehav.2009.09.015

Halfwerk W., Bot S., Buikx J., van der Velde M., Komdeur J., et al. (2011). Low-frequency songs lose their potency in noisy urban conditions. Proceedings of the National Academy of Sciences. 108 (35): 14549-14554. https://doi.org/10.1073/pnas.1109091108

Hanna D., Blouin-Demers G., Wilson D. R., and Mennill D. J. (2011). Anthropogenic noise affects song structure in red-winged blackbirds (Agelaius phoeniceus). Journal of Experimental Biology. 214 (21): 3549-3556. https://doi.org/10.1242/jeb.060194

Johnson L. S. and Kermott L. H. (1991). The functions of song in male house wrens (Troglodytes aedon). Behaviour. 116 (3): $190-209$.

Johnson L. S. and Searcy W. A. (1996). Female attraction to male song in house wrens (Troglodytes aedon). Behaviour. 133 (5): $357-366$.

Johnson L. S., Hicks B. G., and Masters B. S. (2002). Increased cuckoldry as a cost of breeding late for male House Wrens (Troglodytes aedon). Behavioral Ecology. 13 (5): 670-675. https://doi.org/10.1093/beheco/13.5.670

Klump G. M. (2000). Sound localization in birds. In: Comparative Hearing: Birds and Reptiles, edited by Dooling R. J., Fay R. R. and Popper A. N. New York: Springer Verlag. 249-307.

Krebs J. R., Avery M., and Cowie, R. J. (1981). Effect of removal of mate on the singing behaviour of great tits. Animal Behaviour. 29 (2): 635-637. https://doi.org/10.1016/S0003-3472(81)80134-0

Kroodsma D. E., Bereson R. C., Byers B. E., and Minear E. (1989). Use of song types by the chestnut-sided warbler: evidence for both intra-and inter-sexual functions. Canadian Journal of Zoology. 67 (2): 447-456. https://doi.org/10.1139/z89-065

LaBarbera K., Llambías P. E., Cramer E. R., Schaming T. D., and Lovette I. J. (2010). Synchrony does not explain extrapair paternity rate variation in northern or southern house wrens. Behavioral Ecology. 21 (4): 773-780. https://doi.org/10.1093/beheco/arq052

Lambrechts M. M. (1996). Organization of birdsong and constraints on performance. In: Ecology and Evolution of Acoustic Communication in Birds. Ithaca, New York: Cornell University Press, 305-320.

LaZerte S. E., Slabbekoorn H., and Otter K. A. (2016). Learning to cope: vocal adjustment to urban noise is correlated with prior experience in black-capped chickadees. Proceedings of the Royal Society B. 283 (1833): 20161058. https://doi.org/1098/rspb.2016.1058 
LaZerte S. E., Slabbekoorn H., and Otter K. A. (2017). Territorial black-capped chickadee males respond faster to high-than to low-frequency songs in experimentally elevated noise conditions. PeerJ. 5: e3257. https://doi.org/10.7717/peerj.3257

Lenth R. V. (2016). Least-squares means: the (R) package (lsmeans). Journal of Statistical Software. 69 (1): 1-33. https://doi.org/10. 18637/jss.v069.i01

Liu W. C. and Kroodsma D. E. (2007). Dawn and daytime singing behavior of chipping sparrows (Spizella passerina). The Auk. 124 (1): 44-52. https://doi.org/10.1642/0004-8038(2007)124[44:DADSBO]2.0.CO;2

McCabe R. A. (1965). Nest construction by house wrens. The Condor. 67 (3): 229-234.

Mockford E. J. and Marshall R. C. (2009). Effects of urban noise on song and response behaviour in great tits. Proceedings of the Royal Society B. 276 (1669): 2979-2985. https://doi.org/10.1098/rspb.2009.0586

Morales M. (2012). Scientific graphic functions for factorial designs. R program software version 1.1-1. https://doi.org/CRAN.R-project. org/package=sciplot.

Nelson D. A. and Poesel A. (2011). Song length variation serves multiple functions in the white-crowned sparrow. Behavioral Ecology and Sociobiology. 65 (5): 1103-1111. https://doi.org/10.1007/s00265-010-1120-z

Nemeth E. and Brumm H. (2010). Birds and anthropogenic noise: are urban songs adaptive? The American Naturalist. 176 (4): 465-475. https://doi.org/10.1086/656275

Otter K. and Ratcliffe, L. (1993). Changes in singing behavior of male black-capped chickadees (Parus atricapillus) following mate removal. Behavioral Ecology and Sociobiology. 33 (6): 409-141. https://doi.org/10.1007/BF00170256

Otter K., McGregor P. K., Terry A. M., Burford F. R., Peake T. M., and Dabelsteen T. (1999). Do female great tits (Parus major) assess males by eavesdropping? A field study using interactive song playback. Proceedings of the Royal Society B. 266 (1426): 1305-1309. https://doi.org/10.1098/rspb.1999.0779

Pinheiro J, Bates D., DebRoy S., Sarkar D., and R Core Team. (2017). nlme: Linear and Nonlinear Mixed Effects Models. R package version 3.1-131. https://doi.org/CRAN.R-project.org/package=nlme.

Platt M. E. and Ficken M. S. (1987). Organization of singing in house wrens (Troglodytes aedon). Journal of Field Ornithology. 58 (2): 190-197.

Pohl N. U., Slabbekoorn H., Klump G. M., and Langemann, U. (2009). Effects of signal features and environmental noise on signal detection in the great tit, Parus major. Animal Behaviour. 78 (6): 1293-1300. https://doi.org/10.1016/j.anbehav.2009.09.005

Pohl N. U., Leadbeater E., Slabbekoorn H., Klump G. M., and Langemann U. (2012). Great tits in urban noise benefit from high frequencies in song detection and discrimination. Animal Behaviour. 83 (3): 711-721. https://doi.org/10.1016/j.anbehav.2011.12.019

R Core Team. 2016 R: A Language and Environment for Statistical Computing. Vienna, Austria: R Foundation for Statistical Computing. http://www.R-project.org/.

Read J., Jones G., and Radford A. N. (2013). Fitness costs as well as benefits are important when considering responses to anthropogenic noise. Behavioral Ecology. 25 (1): 4-7. https://doi.org/10.1093/beheco/art102

Redondo P., Barrantes G., and Sandoval L. (2013). Urban noise influences vocalization structure in the House Wren Troglodytes aedon. Ibis. 155: 621-625. https://doi.org/10.1111/ibi.12053

Reichard D. G., Rice R. J., Schultz E. M., and Schrock S. E. (2013). Low-amplitude songs produced by male dark-eyed juncos (Junco hyemalis) differ when sung during intra-and inter-sexual interactions. Behaviour. 150 (9-10): 1183-1202. https://doi.org/10.1163/ 1568539X-00003090

Rendall D. and Kaluthota C. D. (2013). Song Organization and variability in northern house wrens (Troglodytes aedon parkmanii). The Auk. 130 (4): 617-628. https://doi.org/10.1525/auk.2013.13069

Ríos-Chelén A. A., Quirós-Guerrero E., Gil D., and Garcia C. M. (2013). Dealing with urban noise: vermilion flycatchers sing longer songs in nosier territories. Behavioral Ecology and Sociobiology. 67 (1): 409-418. https://doi.org/10.1007/s00265-012-1434-0

Ríos-Chelén A. A., Cuatianquiz-Lima C., Bautista A., and Martinez-Gomez M. (2017a). No reliable evidence for immediate noiseinduced song flexibility in a suboscine. Urban Ecosystems. 21: 15-25. https://doi.org/10.1007/s11252-017-0690-1

Ríos-Chelén A. A., McDonald A. N., Berger A., Perry A. C., Krakauer A. H., and Patricelli G. L. (2017b). Do birds vocalize at higher pitch in noise, or is it a matter of measurement?. Behavioral Ecology and Sociobiology. 71 (1): 29. https://doi.org/10.1007/s00265-016-2243-7

Ritchison G. (1995). Characteristics, use and possible functions of the perch songs and chatter calls of male Common Yellowthroats. Condor. 97 (1): 27-38. https://doi.org/10.2307/1368980

Shannon G., McKenna M. F., Angeloni L. M., Crooks K. R., Fristrup K. M., et al. (2015). A synthesis of two decades of research documenting the effects of noise. Biological Reviews. 91 (4): 982-1005. https://doi.org/10.1111/brv.12207

Slabbekoorn H. and den Boer-Visser A. (2006). Cities change the songs of birds. Current Biology. 16 (23): 2326-2331. https://doi.org/ 10.1016/j.cub.2006.10.008

Slabbekoorn H. and Peet M. (2003). Birds sing at a higher pitch in urban noise. Nature. 424 (6946): 267-267. https://doi.org/10.1038/ $424267 \mathrm{a}$

Staicer C. A. (1996). Honest advertisement of pairing status: evidence from a tropical resident wood-warbler. Animal Behaviour. 51 (2): 375-390. https://doi.org/10.1006/anbe.1996.0036

Tove M. H. (1988). Patterns of singing by house wrens with respect to the breeding cycle. PhD thesis, Utah State University.

Verzijden M. N., Ripmeester E. A. P., Ohms V. R., Snelderwaard P., and Slabbekoorn H. (2010). Immediate spectral flexibility in singing chiffchaffs during experimental exposure to highway noise. Journal of Experimental Biology. 213 (15): 2575-2581. https://doi. org/10.1242/jeb.038299

Wiley R. H. and Richards D. G. (1978). Physical constraints on acoustic communication in the atmosphere: Implications for the evolution of animal vocalizations. Behavioral Ecology and Sociobiology. 3: 69-94. https://doi.org/10.1007/BF00300047

Wood W. E. and Yezerinac S. M. (2006). Song sparrow (Melospiza melodia) song varies with urban noise. The Auk. 123 (3): 650-659. https://doi.org/10.1642/0004-8038(2006)123[650:SSMMSV]2.0.CO;2

Zollinger S. A., Podos J., Nemeth E., Goller F., and Brumm H. (2012). On the relationship between, and measurement of, amplitude and frequency in birdsong. Animal Behaviour. 84: e1-e9. https://doi.org/10.1016/j.anbehav.2012.04.026 